\title{
LUT
}

Lappeenranta

University of Technology

\section{Simulation of Wind Powered Hydraulic Heating System}

Roozbahani Hamid, Herpiö Juha-Matti, Ăman Rafael, Handroos Heikki

This is a Final draft

version of a publication

published by IEEE

in IEEE Global Fluid Power Society Symposium 2018

DOI: $10.1109 /$ GFPS.2018.8472387

Copyright of the original publication: (C) IEEE 2018

Please cite the publication as follows:

Roozbahani H., Herpiö J., Ăman R., Handroos H. (2018). Simulation of Wind Powered Hydraulic Heating System. IEEE Global Fluid Power Society Symposium 2018. DOI: 10.1109/ GFPS.2018.8472387 


\title{
Simulation of Wind Powered Hydraulic Heating System
}

\author{
Hamid Roozbahani $^{1^{*}}$, Juha-Matti Herpiö ${ }^{2}$, Rafael Åman ${ }^{3}$, Heikki Handroos ${ }^{4}$ \\ 1, 3, 4 Lappeenranta University of Technology, Lappeenranta, Finland \\ ${ }^{2}$ Sarlin $O y$ Ab, Vantaa, Finland \\ ${ }^{*}$ Corresponding Author: hamid.roozbahani@lut.fi, +358406783948
}

\begin{abstract}
The objective of this paper is to design and simulate a wind powered hydraulic heating system that can operate independently in remote places where the use of electricity is not possible. Components for the system were to be selected in such a way that the conditions for manufacture, use and economic viability are the as good as possible. Savonius rotor is chosen for wind turbine, due to its low cut in speed and robust design. Savonius rotor produces kinetic energy in wide wind speed range and it can withstand high wind gusts. Radial piston pump is chosen for the flow source of the hydraulic heater. Pump type is selected due to its characteristics in low rotation speeds and high efficiency. Volume flow from the pump is passed through the throttle orifice. Pressure drop over the orifice causes the hydraulic oil to heat up and, thus, creating thermal energy. Thermal energy in the oil is led to radiator where it conducts heat to the environment. The hydraulic heating system is simulated. For this purpose, a mathematical models of chosen components were created. In simulation wind data gathered by Finnish meteorological institute for 167 hours is used as input. The highest produced power is achieved by changing the orifice diameter so that the rotor tip speed ratio follows the power curve. This is not possible to achieve without using electricity. Thus, for the orifice diameter only one, the optimal value is defined. Results from the simulation were compared with investment calculations. Different parameters effecting the investment profitability were altered in sensitivity analyses in order to define the points of investment profitability. Investment is found to be profitable only with high average wind speeds.
\end{abstract}

Keywords-Savonius Rotor, Fluid power circuit, Thermal power, Throttling, Investment

\section{I.INTRODUCTION}

Technologies to produce energy from renewable sources are being constantly developed to produce energy more efficiently and more profitable. Wind energy is one of the most studied and developed technologies among renewable energy technologies. Turbine output and sizes are increasing as the total net amount of produced energy. Fluid power system is a conventional and reliable way to transfer power in machines. In normal operation the friction and restrictions in the pipeline create power losses and that are creating heat to the system. This eventually leads to temperature increase while viscosity will decrease. Also the oil will deteriorate and lose lubrication properties. Typically, the temperature of the oil is controlled with a cooler that radiates the excessive heat to the atmosphere.

With wind powered hydraulic pump heat can be created directly from the wind. This configuration allows the use of heat in remote places that are often outside the coverage of the electrical grid. The hypothesis of this paper is to simulate a system that can transform the wind power to thermal power in a hydraulic system.
First the basic concepts and equipment were described for wind power and fluid power systems. Literature survey was conducted to acquire required information about wind turbines, hydraulic wind turbines, fluid power systems and heat generation. The parameters and the components used in the actual simulation model were chosen according this survey. The main idea behind the concept design was to keep the design affordable, viable, as simple and as efficient as possible. Unit will be used to produce constant heat energy in remote places and outside the coverage of the electrical grid. This means that the unit should be transportable and reliable. Savonius rotor, radial piston pump and simple orifice were selected as main components for the simulation.

In this research Simulink was used to create a mathematical model of wind powered hydraulic heat source. A model for commercially available parts was simulated. Second simulation model was done for empirical research purposes for test bench control and verification of the results. Pressure in the fluid power system resists the rotational energy of the turbine. This leads to varying optimal tip speed ratio. Tip speed ratio can be controlled by chancing the orifice area. With optimal tip speed ratio, the unit creates highest thermal energy output.

Second hypothesis was to estimate out of simulation results the profitability of wind powered heating system. With given parameters the unit was not found to be profitable.

\section{II.DESCRIPTION OF TECHNOLOGIES}

In this section there are descriptions of all mechanical components related to this work. This section also includes the literature survey.

\section{A. Simulation}

Real-time simulation is widely used in research and development projects. Simulation model is mathematical presentation of the system and it is used to solve physical properties and their interactions. With simulation it is possible to iterate the suitable parameters for prototyping while decreasing the lead time and costs.

\section{B. Wind turbines}

Wind offers an abundant resource of energy. Wind turbines are being used to transform wind energy in to a mechanical energy. The wind is causing drag and lift forces against the turbine geometry that are causing the turbine shaft to rotate. This rotational mechanical energy is then converted into other types of energy using mechanical components. Typical solutions are a generator to produce electrical energy or pumps to produce hydraulic energy. Wind turbines are divided in to categories by their operating principles 
and blade design. This division is based on their axis orientation. Horizontal Axis Wind Turbines (HAWT) are horizontally rotating turbines which are more common in current commercial high power applications. Vertical Axis Wind Turbines (VAWT) are vertically rotating turbines that are being used in rural areas for water pumping and battery charging.

Turbine families and their aero-dynamical power coefficient $C_{p}$ are presented in Fig. 1, in relation with tip speed ratio. Power coefficient describes the maximum amount of energy turbine can extract from the wind while the Ideal Betz limit is the defined upper limit of efficiency. Essential wind turbine parameter is tip speed ratio $\lambda$ what describes the velocity of the rotor tip compared the current wind speed.

$\lambda=\frac{\omega \times r}{v}$

where $w$ is angular speed $[\mathrm{rad} / \mathrm{s}], r$ is radius [m] of the rotor and $v$ is the velocity of the wind $[\mathrm{m} / \mathrm{s}]$.

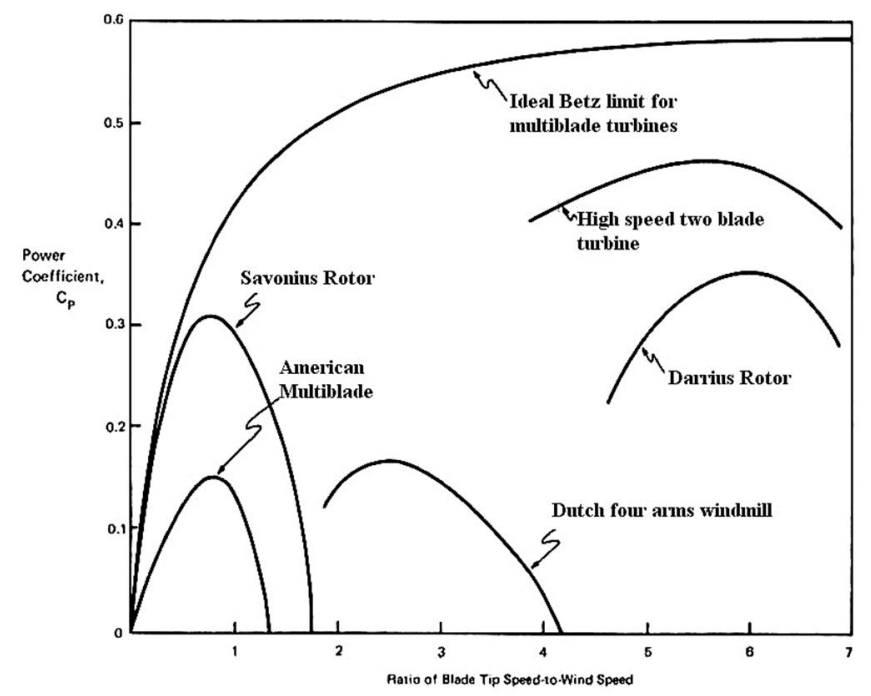

Fig. 1: Wind turbine power coefficient $\mathrm{Cp}$ as a function of the tip speed ratio. [1]

Modern large HAWT are state of the art units that rotate on variable speed to generate the required tip-speed ratio for maximum power output. Optimal tip speed ratio is achieved with a sophisticated multi variable control that regulates the pitch angle of the turbine blades and the yaw angle of the nacelle. Turbine rated output and blade aerodynamics set limitations to the wind speed under which the turbine can operate. Blade aerodynamics and frictional forces of drivetrain resist the forces of the wind. Cut-in wind speed is required to overcome the mechanical losses of the turbine. In high wind speed situation, the control system changes the pitch angle to reduce the blade area affected to the wind. If wind speed goes over cut-out wind speed the turbine will shut down. [2]

VAWT are typically used in low power applications that withstand high wind speeds and variable wind situations. Turbines are also independent from the wind direction and turbulences since it rotates around vertical axis. VAWT's operate in variable speeds and this allows the turbines to harvest the energy from the wind in low and high wind speeds. Drag based turbines also generate high starting torque. Constant rotation of the turbine allows the drag force based VAWT's to be used in pumping and battery charging applications. VAWT's has lower coefficient of performance compared to HAWT's. [3, p.20-22] Performance coefficient describes energy harvesting capability of the turbine in relation with blade tip speed and wind speed.

\section{Hydraulic wind turbines}

Wind turbines combined with hydrostatic system are being developed to reduce the need of frequency converter and gearbox. Hydrostatic powertrain simplifies the maintenance and layout of components in nacelle. Large scale hydraulic wind turbines are under development and Mitsubishi is commissioning 2015 in Scotland a 7 MW project called Sea Horse. This variable speed turbine is coupled to a hydraulic pump witch is connected to hydraulic motor. Speed of the motor is regulated with valves to achieve constant speed to the synchronous generator. This configuration increases the efficiency because there are no losses due to power conversion. [4]

\section{Savonius rotors}

Savonius rotor is a drag force rotor developed in 1920's by Finnish Captain Sigurd Savonius. In his research he experimented the rotor type with most of the augmentations discussed later on in next chapter. Benefits for Savonius rotors are the simplicity of the construction, inexpensive materials and low noise levels. Rotors also require low start-up torque in low wind speeds. Variations in wind direction does not affect the performance of the rotor. [5] Since rotors are self-starting they do not require control logic or electrical components to operate.

Savonius wind rotor is highly reliable and can be operated in winds up to $60 \mathrm{~m} / \mathrm{s}$. Savonius rotor maintenance is easy since the only task is to grease the bearings according the manufacturers recommendations. VAWT are found to require much less area in wind farms since they are independent to the turbulent flow situations, caused by parallel units. This allows placement of several turbine units in a wind farm area. [6]. The aerodynamic performance of Savonius rotors has been studied in several publications. Aspect ratio of height and radius [7], overlap of the buckets [8], helical formation of the wings [9], size of the end plates [5] and number of buckets $[5,10]$ have been investigated to improve the performance of Savonius rotor.

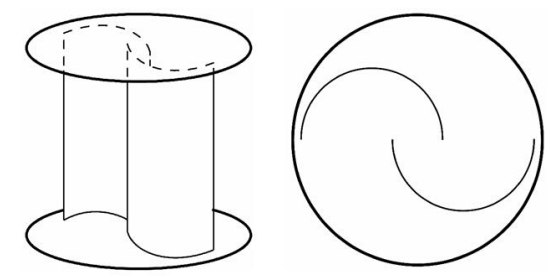

Fig. 2: Typical Savonius rotor with end plates. The gap between the buckets is called overlap. [Figure:11]

Relation between diameter and height is called the aspect ratio $A_{S}$.

$A_{s}=\frac{h}{d}$

where $h$ is height of the rotor [m] and $d$ is the diameter of the rotor [m]. Overlap of the rotor buckets, $G$, have positive effect to the overall performance of the rotor. Flow through the 
overlap creates pressure increase in concave side of the returning blade this increases the torque of the returning blade. [8]

$$
G=\frac{a}{d}
$$

where $a$ is overlap distance $[\mathrm{m}]$. By combining these findings, it is possible tune the performance of the Savonius rotor. In Fig. 2 [12] torque coefficient of typical rotor and rotor with undescribed augmentators are presented. Darrieus-Savonius-rotor is a combination of Savonius rotor and Darrieus rotor. Darrieus rotor is VAWT lift force based rotor. This combination has been studied and it has higher power efficiency than either rotor type alone. This combination is also seen as good VAWT configuration since it is self-starting in low wind speeds. [13]

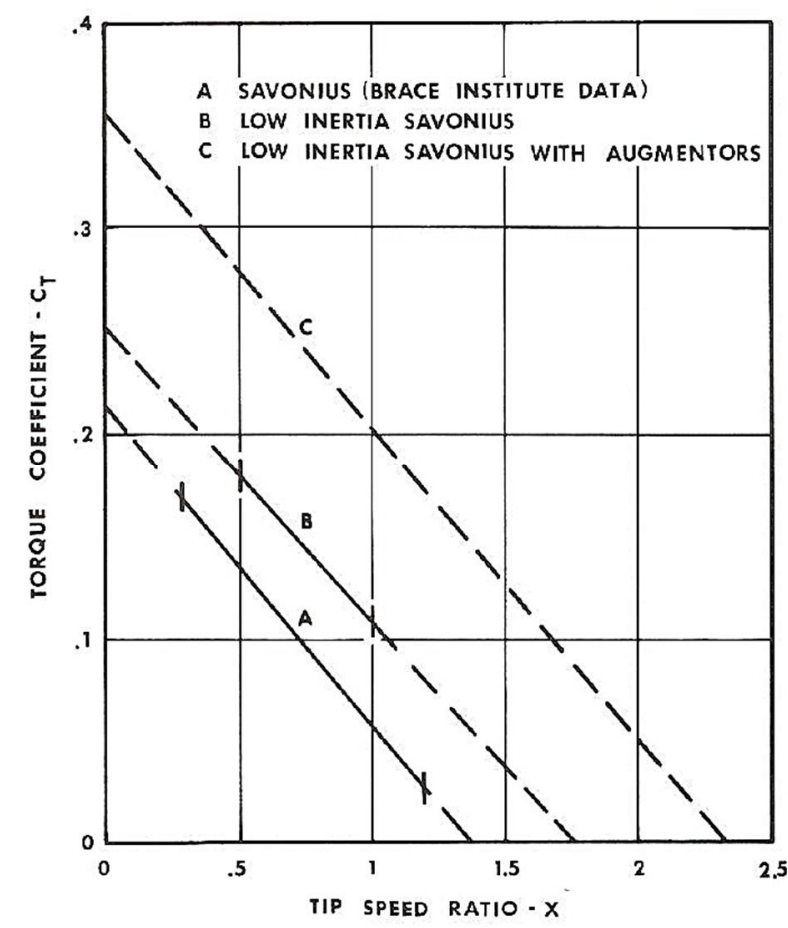

Fig. 3: Torque Coefficient and tip speed ratio for Savonius rotors [12]

Tip speed ratio is related to the torque generated by the rotor. In Fig. 3 we can see that the torque generated by the rotor is linear. From this diagram we can calculate the torque coefficient $C_{t}(\lambda)$ as a function of tip speed ratio $(\lambda)$.

$C_{t}(\lambda)=y_{c t}-k \lambda$

where $y_{c t}$ is the point, curve crosses the $\mathrm{y}$-axis and $k$ is slope of curve. Total torque of the rotor $T_{w t}$ is calculated with following equation (5). By changing the area effected by the wind and radius of the rotor we can increase the torque generated by the rotor.

$T_{w t}=\frac{1}{2} \rho C_{t}(\lambda) v^{2} A r$

where $\rho$ is air density $\left[\mathrm{kg} / \mathrm{m}^{3}\right]$ and $A$ is rotor cross-section area $\left[\mathrm{m}^{2}\right]$. Coupled pump and inertia of the rotor resists the rotation.

$J \ddot{\theta}-T_{w t}-T_{p}=0$ where $J$ is inertia $\left[\mathrm{kg} / \mathrm{m}^{2}\right]$ of the rotor, $e$ is angular acceleration $\left[\mathrm{rad} / \mathrm{s}^{2}\right]$ and $T_{p}$ is torque of the pump described in equation (12). Inertia of the turbine is being calculated according equation (7). This is basic equation for discs. We can assume that the mass $m$ is distributed evenly along the radius as in equation (7).

$J=\frac{1}{2} m r^{2}$

Angular acceleration is calculated with equation:

$\ddot{\theta}=\frac{T_{w t}+T_{p}}{J}$

By integrating the angular acceleration, we get the angular speed $\theta^{\prime}$ of the shaft. As a symbol of the angular speed can be used here either $\theta^{\prime}$ or $w$.

$\dot{\theta}=\int \ddot{\theta}$

In vertical axis turbines it is possible to use long shaft and coupling to lower the pump to the same height as the oil tank. This allows the unit installation to the same height as the pump. This configuration affects also to the piping length, since long lines are avoided.

\section{E. Brake system}

Braking of the hydraulic wind turbine is done with a mechanical brake. Small scale electrical turbines use commonly a brake resistor. High output HAWT's uses blade pitch control and yaw control to reduce the blade area affected to the wind. In case of high winds, the control system should drive the turbine to stall and continue the normal operation once the wind speeds are suitable for safe use of the turbine. This system requires mechanical brake and a feedback from the turbine speed also auxiliary wind speed measurement is considered to sense the wind speed after the turbine has been stopped due to high speed wind.

\section{F. Fluid power circuit}

Fluid power circuit transfers the hydraulic power and it includes all components that are connected or operated with hydraulic fluid. In simulation of fluid power circuit, the lumped parameter model is used. In lumped parameter model the circuit is divided in to volumes and parts that operate under certain assumptions and allows the use of ordinary differential equations to solve physical parameters of the simulated system. [14]

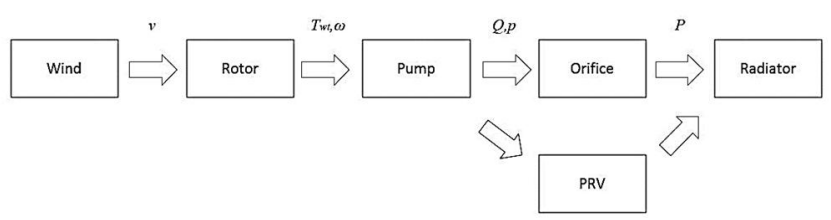

Fig. 4: Lumped element model of simulation.

In modelling of hydraulic components analytical and semiempirical models are being used. Analytical model is based on physical laws and constants and semi-empirical model is 
a combination of empirical- and analytical model combined to form a practical model for component or phenomenon. [15]. Effective bulk modulus $\beta_{e}$ measures the hydraulic circuit resistance to uniform compression. The first time derivative of pressure $p^{\prime}$, in the pipe can be calculated with equation (10). According lumped parameter model all equations used to simulate hydraulic system interact with each other. In lumped parameter model the pressure is evenly distributed in the volume.

$\dot{p}=\frac{\beta_{e}}{V_{p}}\left(Q_{p}-Q_{p r v}-Q_{o}\right)$

where $V_{p}$ is volume of the pipe, $Q_{p}$ is volume flow of pump, $Q_{p r v}$ is volume flow of pressure relief valve and $Q_{0}$ is volume flow of orifice.

In fluid systems the flow is divided in to laminar and turbulent flow areas. Laminar flow is ideal in typical hydraulic circuits since flow resistance in the tube increases linearly. Laminar flow is not common in practice. In turbulent flow the flow resistance increases exponentially and this phenomenon cannot be avoided in hydraulic components where the flow is restricted such as valves and orifices. [16, p.44] In hydraulic circuits the flow is typically turbulent. [16, p.51]. Pressure losses from friction or flow resistance outside the pressure regulating actuator are causing losses to the fluid power circuit. These losses are not taken into account since the overall pressure difference is the phenomenon under research.

In cavitation the pressure decreases under the ambient pressure and in some point crosses the fluid evaporation pressure. This causes the fluid to evaporate causing bubbles to the liquid. When these bubbles are under high pressure again they start to shrink and finally the will collapse causing pressure shock. These pressure shocks are causing erosion and excessive wear in metal parts. Cavitation is common phenomenon in suction pipes and in orifices where the pressure suddenly decreases. [17] While the system is being started at low temperatures the possibility of cavitation is high since the cool fluid has higher viscosity that creates pressure drop. In low temperature starts, system might require external heating. The safe temperature limits can be chosen from the characteristic curves of the oil being used.

Due to viscous friction of the fluid, mechanical clearances and mechanical friction system suffers losses to initial power input. These losses are described as efficiencies. Volumetric efficiency is related to the internal leakages hence reducing the rated flow of the pump. Hydro mechanical efficiency is related to friction and flow conditions. Hydro mechanical efficiency reduces rated pressure difference. These efficiencies represent together total efficiency of the system [16, p. 77]. Typically the pipeline consists of steel pipes and flexible hoses. As a rules of thumb, all pipes diameters are selected so that the flow rate in the pressure lines is 3 to $5 \mathrm{~m} / \mathrm{s}$ to avoid friction. For the suction line flow rate from 0,5 to $1,5 \mathrm{~m} / \mathrm{s}$ is recommended to avoid cavitation. [18, p. 704] Optimal cross-sectional area for the pipe $\mathrm{A},\left[\mathrm{m}^{2}\right]$ is calculated with an equation:

$A=\frac{Q}{v}$ where $v$ is the fluid velocity $[\mathrm{m} / \mathrm{s}]$ and $Q$ is pipe crosssectional area $\left[\mathrm{m}^{3} / \mathrm{s}\right]$. Capacity in the inlet line has to be sufficient for booster- and main pump production. The volume of the tank is dimensioned to be 10 times the maximum volume flow of the pump. All low pressure side components have to be chosen so that the pressure difference at the maximum flow does not increase over the maximum value. Suction filter is chosen to fulfil the flow quantity of the pump and possible booster pump unit. Hydraulic unit is stationary and being protected by a weather proof housing leads to good protection against all external defects. Oil has to be changed during the oil change interval and cleanliness has to be maintained. Component families of hydraulic valves and pumps allows to scale and modify the hydraulic power system designs for optimal power production.

\section{G. Variable speed pump}

Hydraulic pump is coupled to the wind turbine which is rotating in low speeds. Therefore, the system requires a hydraulic pump that is capable of operating at low speeds. Radial piston pumps are suitable for variable and low speed systems. [19, p.139] Pump requires in certain situations a booster pump in low rotation speeds to avoid cavitation. [16, p.116]. Radial piston pump uses eccentric profile plate to move pistons that are oriented in a radial fashion within the cylinder block. As the rotor turns the pistons follow the profile of the rotor, thereby drawing fluid in to the intake side of the pump, with the help of spring and pushing the fluid out of the discharge side of the pump [20, p.260]. Piston pumps have also high efficiencies since the geometry of the cylinder and piston allows low clearances. Pump torque $T_{p}$ and volume flow $Q_{p}$ are calculated using equations 12 and 13:

$$
\begin{aligned}
& T_{p}=\frac{V_{k} \Delta p}{2 \pi} \\
& Q_{p}=\frac{V_{k} \dot{\theta} \eta}{2 \pi}
\end{aligned}
$$

where $V_{k}$ is displacement $\left[\mathrm{m}^{3} / \mathrm{rev}\right]$ of the pump and efficiency of the pump.

\section{H. Hydraulic throttle orifice}

With a throttle it is possible to regulate the volume flow and the pressure of the system. Throttle can be electronically actuated or mechanically operating valve. The purpose of throttle valve in this research is to create a pressure drop in order to create heat. Flow through the ports is turbulent since the velocity of the fluid increases when passing orifices of the valve. Flow situations across the orifice is presented in Fig. 5.

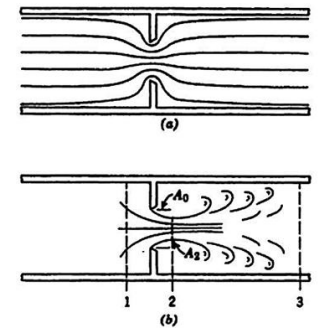

Fig. 5: Flow through an orifice: (a) laminar flow; (b) turbulent flow. [21] 
Simple analytical model of the orifice is used to produce the needed optimal pressure drop over the throttle orifice. Orifice is created with a needle valve. Needle valve needs to be calibrated and maintained regularly to avoid changes in optimal setting. In simulation the orifice is considered to be round and the adjusted parameter is orifice diameter. Volume flow through the orifice, $Q_{0}$, is calculated with equation (14)

$Q_{o}=C_{d} A_{o} \sqrt{\frac{2}{\rho}} \sqrt{|p|} \frac{p}{|p|}$

where $C_{d}$ is the discharge coefficient, $A_{0}$ is cross-section of the orifice, is density of the hydraulic fluid and $p$ is pressure drop across the orifice.

\section{Pressure relief valve}

Pressure Relief Valve (PRV) is a typical component of a hydraulic circuit. The main function of this device is to remove the excess oil from the system in case of the over pressure. This is a safety measure to prevent the system failure due to high pressure. Valve has an inlet and an outlet port and the flow between the ports is controlled by a spring adjusted stem. Pressure relief valve is presented in Fig. 6. Port $\mathrm{P}$ presents the pressure port and $\mathrm{T}$ presents the ports that are connected to the tank.
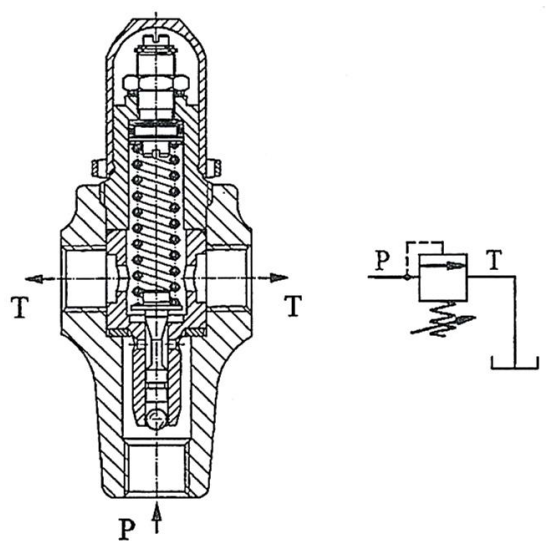

Fig. 6: Cross-sectional view of pressure relief valve and symbol. [16]

The volume flow, $Q_{p r v}$, through the PRV is calculated using a semi-empirical model using equation (15). [22] With this model it is possible to solve the flow by using parameters $\mathrm{C}_{1}$ and $\mathrm{C}_{2}$. These parameters are identified from experimental results of the valve.

$Q_{p r v}=\frac{p-p_{r e f f}}{\frac{C_{1}}{\sqrt{p}}+C_{2} \sqrt{p}}$

where $p_{\text {reff }}$ is the reference pressure of the PRV and $p$ is fluid pressure $[\mathrm{Pa}]$. The values for the parameters $\mathrm{C}_{1}$ and $\mathrm{C}_{2}$ are calculated from characteristic curve of valve NG15.

\section{J. Hydraulic oils}

Hydraulic oil is essential part of hydraulic power circuit since it transfers the hydraulic power in the system. It has good lubricating characteristics and it contains additives and protective agents that conserve and protect the hydraulic circuit. Specific heat for hydraulic oil, used in this work, is $1800 \mathrm{~J} /(\mathrm{kgK})$ where specific heat for water is $4185 \mathrm{~J} /(\mathrm{kgK})$. The viscosity of the hydraulic oil is dependent of the temperature and pressure. When the temperature increases the viscosity decreases and when the pressure rises the viscosity increases. Since temperature of the oil is being controlled and maintained constant, viscosity in system under study stays constant. In normal operating pressures the effect to the viscosity is insignificant [16, p.42]

Bulk modulus of oil $B_{\mathrm{oil}}[\mathrm{Pa}]$ is a property to express the compressibility of the fluid. Oil is typically the most compressible part of the circuit. Temperature and the pressure are effecting to bulk modulus. If the unit consists of long lines of flexible hose or air is present in the system, effective bulk modulus has to be calculated separately. Since air is more compressible than oil, air bubbles create disturbances to the effective bulk modulus by decreasing it. Low viscosity of the oil affects the air separation rate by increasing it. Homogenous fluid has a constant bulk modulus in this research. Water, oxygen and wear particles are causing the oil to lose the lubricating capabilities and oil has to be replaced after the oil characteristics have fallen under the acceptable set points. This oil change interval is set after oil analyses.

\section{K. Heat transfer}

Hydraulic system described in this study is according thermodynamics an isentropic system. Isentropic processes have constant entropy. It is a reversible adiabatic process. This means that there is only work being added to the system and heat is generated from work. In hydraulic systems friction and rapid changes in velocity and flow direction causes power losses. These changes create heat as power loss. Heat is transferred in a body when there is a temperature difference between the bodies. There are three ways of heat transfer. Conduction occurs when a temperature gradient exists in a body. Conduction happens when energy is being transferred from the high-temperature region to the low-temperature region. [23, p.11]

Convection occurs when a gas or liquid is being used to change the thermal energy balance in a body. The heat transfers to the moving element or vice versa. Radiator in mobile devices works through convection. Radiation is heat transfer from a body by means of electromagnetic radiation what is caused by the thermal energy of the body. Heat is being generated in the fluid power systems from various sources. Typical sources of heat in hydraulic systems are pumps, valves and actuators. All components that produce pressure drop. Components need lubrication and to accomplish this there has to be tolerances where the lubricating hydraulic oil must flow. Damaged pipes and components, such as leaking seals and excessive tolerances are typical heat sources.

Heat transfer in fluid power system is considered typically as a loss since this heat has to be taken out from the system with a heat exchanger or design and operate the system so that the excessive heat radiates during normal operation. Insulation is not typically used in hydraulic system since the heat should be avoided. In this study all component is considered as insulated parts and the only heat sink under investigation is radiator. Newton's law of cooling (16) is used to solve the radiator power $P_{r}$, 
$P_{r}=h_{t} A\left(T_{0}-T_{\infty}\right)$

where $h_{t}$ is convective heat-transfer coefficient $\left[\mathrm{W} / \mathrm{m}^{2} \mathrm{~K}\right]$ of the radiator, $A$ is radiative area $\left[\mathrm{m}^{2}\right], T_{0}$ is temperature $[\mathrm{K}]$ of oil and $T_{\infty}$ is temperature $[\mathrm{K}]$ of air. Convection heat-transfer coefficient describes the radiator capability to convert the thermal energy between bodies or fluids. Convection heattransfer coefficient for the radiator can be solved experimentally. [23, p. 13]. With Eq. (17) the thermal power, $P_{h}$, from the pressure drop can be calculated.

$P_{h}=Q_{p} \Delta P$

where $Q_{p}$ is volume flow $\left[\mathrm{m}^{3} / \mathrm{s}\right]$ of the pump and $\Delta P$ is pressure difference over orifice. Thermal power to the tank $P_{t}$ is calculated with equation (18)

$P_{t}=P_{h}-P_{r}$

\section{Oil-water heat exchanger}

Oil -water heat exchanger is typical component in industrial systems. The main purpose is to transfer the thermal energy from the oil to the cooling liquid. This transfer rate can be controlled with a temperature measurements and variable speed pump. By decreasing and controlling the oil temperature it is possible to increase the operation hours and lubricating properties of oil and components.

\section{Oil-air heat exchanger}

Oil-Air heat exchanger, also known as radiator, is typical component in mobile applications. With a temperature controlled fan and louver set, operator can control the temperature of the system and direct the excessive heat to the surroundings. Fan motor can be hydraulic driven and controlled using a thermostat valve.

When the inlet temperature exceeds the set point, the fan is started and the louvers direct the heated air to the surroundings. Radiator direct the heat constantly according to temperature difference. In this paper radiator is free convection component so it does not use fan for forced convection.

\section{N. Oil tank}

Oil tank is fixed container for the hydraulic oil. It can be either pressurized or it can breathe freely to the surroundings. In pressurized systems the pump suction line can pressurized with the tank pressure. In this study the oil tank unpressurized and used as a thermal accumulator for energy storage. Temperature increase in the tank is being calculated as follows.

$T_{t}=\frac{P_{t}}{\rho V_{t} C_{v}}+T_{0}$

where temperature in the tank in the beginning of the series is $T_{0}$ and $C_{v}$ is specific heat $[\mathrm{J} / \mathrm{kgK}]$. Oil tank conducts the oil heat to surroundings. This will lead to heat losses if the tank is not insulated or installed to a place where conducted energy cannot be used. Radiative heat power from the tank can be calculated with Eq. 16.

\section{III.METHODS}

Two different systems were simulated. The first system consists of commercially available rotor that is coupled to piston pump. Fluid power circuit is optimized for rotor and pump output.

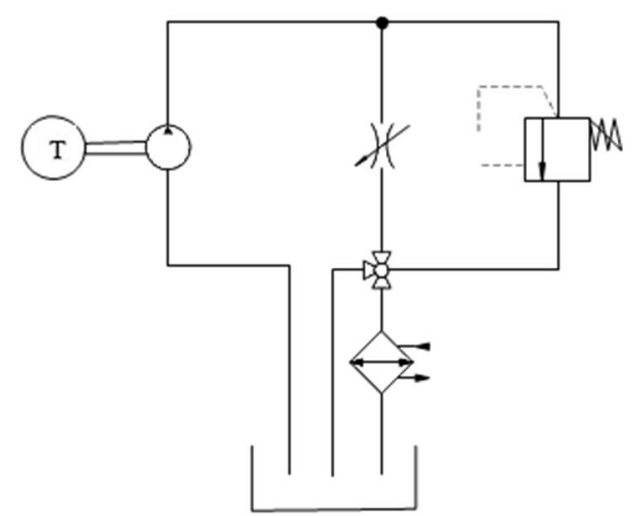

Fig. 7: Simulated fluid power circuit.

The Second model of fluid power circuit assembled in the Laboratory of Intelligent Machines (LUT).

\section{A. Wind data}

Simulating the wind turbine and the fluid power circuit is carried out using real measured wind data. Wind speed input for the simulation comes from 167 hours' wind data from Southern Finland, Kumpula weather station, measured in February 2014. This period was randomly selected. It should be noted that in Finland the wind speeds are higher during winter months. Measurement is 10 minutes' average so it cuts down wind gusts. The measurement altitude is 10 meters above ground level. [24] During this period the wind speed was moderate and it can be considered as normal situation since it adapts to normal average.

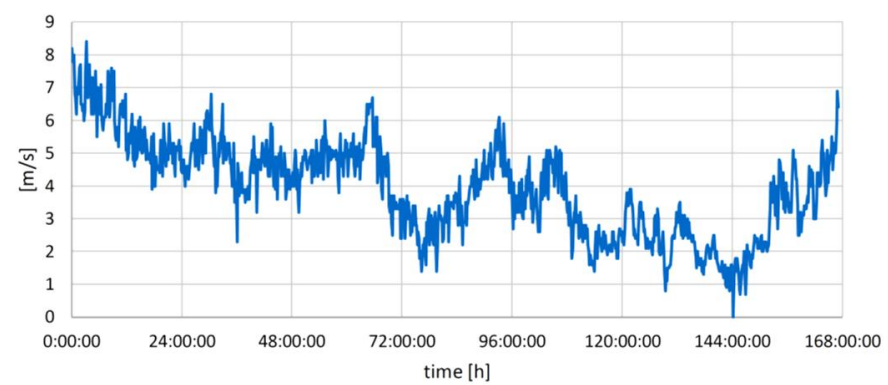

Fig. 8: Wind speed input used in simulation [m/s]. [25]

\section{B. Investment}

The main purpose of investment is to produce revenues to the investor. All commercial investments are divided to either financial- or capital investments. Financial investments are done in capital markets and they include e.g. bonds, stocks and securities. Capital investments are done traditionally in companies and their main purpose is to increase revenues during several years. Investments are not considered as an expenses for the year they are finished. The expenses will be divided to several years and this is called investment hold time or duration of the investment. 


\section{Investment calculations}

With investment calculations the investor seeks to ascertain the profitability of the investment by estimating all the incomes, costs and possible revenues during the investment hold time. Payback period is common method to estimate the profitability of investments. It is suitable for short-term and inexpensive projects since it does not take to account long time investment costs such as interest rates. Payback period is calculated by dividing the total investment with annual net profit. In net present value, NPV, method all annual costs and incomes are discounted to the same period of time. This is usually the time when the total investment is released. Investment can be considered as profitable if the net present value is greater than total investment costs.

$N P V=\sum_{i=1}^{n} \frac{\text { values }_{i}}{(1+\text { rate })^{i}}$

In method of internal rate of return, IRR, investor compares the investment and the profits against interest rate. If internal rate of return is greater than the expected return on capital employed is investment profitable.

\section{Uncertainty factors of the investment}

During the duration of the investment the parameters affecting the investment profitability might change. These changes have to be taken into account to estimate investment tolerance against changes.

\section{E. Assumptions for the investment}

For evaluating the profitability of the investment, various assumptions are required. These assumptions can be changed later in sensitivity analysis to solve the most critical parameters for the investment. Unit capital costs includes costs for wind rotor, hydraulic unit, heating unit, housing, installations, transportation and commissioning on-site. Duration of the investment is considered to be 20 years. During this time no major overhaul for the system is necessary under normal operating conditions.

Costs per annum are the maintenance costs and other variable costs. Costs are considered to be fixed since the unit will be in production round the year. Energy price assumption is based on district heating average prices in Finland after 2nd quarter of 2014. These prices were between 76,34 - 99,70 €/MWh for companies that produces district heating as a primary product. [26]. Electricity price average in Finland according to Finnish energy authority (Energiamarkkinavirasto) is $5,85 \mathrm{cnt} / \mathrm{kW}$. [27] This assumption is not fully compatible with the hydraulic wind turbine application but it will give good indication about the profitability of the investment against traditional energy production methods.

Energy tariff is granted to support renewable energy projects. Energy tariff for wind power is granted only for electricity production and is not suitable for this estimation. Interest rate will be fixed to $6 \%$ and it will remain the same in calculations since we assume that the capital investment was done with one-time payment. Wind speed is investment analyze will follow the Southern Finland wind profile that is described in Fig. 8. Wind rotor torque coefficient is important factor in estimations. This parameter can also affect to some other parameters as capital costs but this possibility is neglected after previous studies and budget price received from manufacturer. Rotor torque coefficient is $C_{t}=$ 0,35 .

\section{F. Sensitivity analyses}

In sensitivity analyze assumed key parameters are manipulated to sort out the most affecting assumptions and to estimate the critical threshold for profitability.

\section{IV.RESULTS}

\section{A. Simulation of the system using Simulink}

Simulation parameters in Simulink are fixed step size and used integrator is fourth order Runge-Kutta. Integrator time step length $T$ is variable. Fixed steps of $1 \mathrm{~ms}$ and $5 \mathrm{~ms}$ were used. The shorter step length did not improve the accuracy of results significantly. This resulted the use of longer $5 \mathrm{~ms}$ step length. With $5 \mathrm{~ms}$ time step length the simulation contains less data points and it keeps the simulation more stable. Simulation time is depending on the wind data. Data sets of the wind speed consisted 1003 samples, ten minutes' interval and arithmetic average wind speed was $3,94 \mathrm{~m} / \mathrm{s}$. Root mean square (RMS) for the wind was $4,44 \mathrm{~m} / \mathrm{s}$. Data sets of the wind speed had to be shortened and sample time was reduced to 10020 seconds. This means that the 10 minutes' sample rate is truncated to 10 seconds.

Initial values have been added to the Simulink model in order to avoid situation in which zero values corrupt the simulation in the beginning. These initial values include wind speed, atmospheric pressure in pipe between pump and orifice and pump flow. These initial values apply only in the first time step of the simulation and does not affect to the later results of simulation. Small values in pressure pipe volume between pump and throttle orifice caused the system to become stiff which influenced the numerical integrator stability.

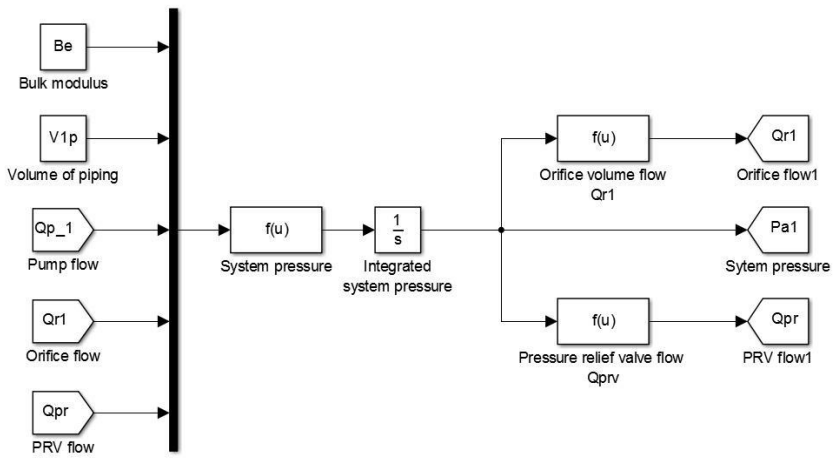

Fig. 9: Example of simulation model in Simulink.

\section{B. Simulation of the wind rotor}

Simulation parameters and results were verified with real Savonius rotor generator power curves. This was done by comparing the generator power curves to simulated thermal power curves. The power and torque matched with the real life model sufficiently. These comparisons are not possible to present here since the author does not have permission from the manufacturer. Torque coefficient for turbine model has to be set for line $\mathrm{C}$ in Fig. 3 (Low inertia Savonius with 
Augmentators) $C_{t}=0,35$ to achieve the same power as the commercial rotor. Simulated rotor coupled to fluid power circuit did not achieve optimal power coefficient presented in Fig. 1.

Optimal tip speed ratio is required for the rotor to transform maximum amount of wind energy to mechanical energy. Optimal tip speed ratio is achieved by adjusting the throttle orifice. Constant wind speed of $10 \mathrm{~m} / \mathrm{s}$ were used to calculate optimal tip speed ratio. Different torque coefficient $C_{t}$ were used to study parameter effect for generated power and optimal tip speed ratio $\lambda$. These effects are presented in Fig. 10

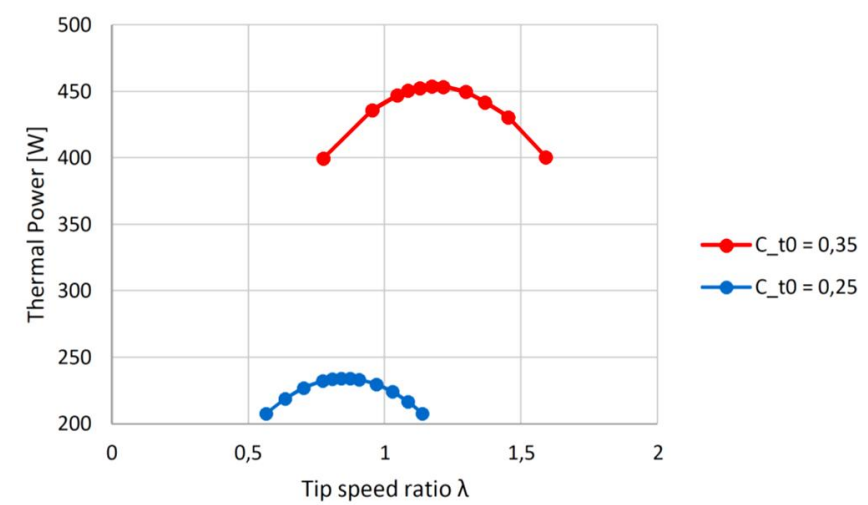

Fig. 10: Optimal tip speed ratio for different torque coefficient curves.

Optimal tip speed at the wind speed of $10 \mathrm{~m} / \mathrm{s}$ for the rotor $\left(C_{t}=0,35\right)$ is 1,17 and for rotor $\left(C_{t}=0,25\right)$ is 0,84 . Simulation of the hydraulic pump The radial piston pump is simulated. It produces volume flow in proportion to input shaft rotational speed. Total pump efficiency changes depending the speed of the pump. In literature typical optimal total efficiency for radial piston pumps varies between 88 and $92 \%$ [16, p. 116]. In simulation constant efficiency of $88 \%$ is used for the pump. From radial piston pump family was pump with displacement of $42 \mathrm{~cm}^{3} / \mathrm{rev}$ selected. Smaller pump size lead to smaller orifice size and to reduced reaction speed.

In Fig. 11 the pump size is being altered to estimate the effect to the overall thermal power production. For the rotor $\left(C_{t}=0,35\right)$ was used and pump sizes were 42 $\mathrm{cm}^{3} / \mathrm{rev}$ and $63 \mathrm{~cm}^{3} / \mathrm{rev}$. Wind speed pulse of $12 \mathrm{~m} / \mathrm{s}$ is used for input.

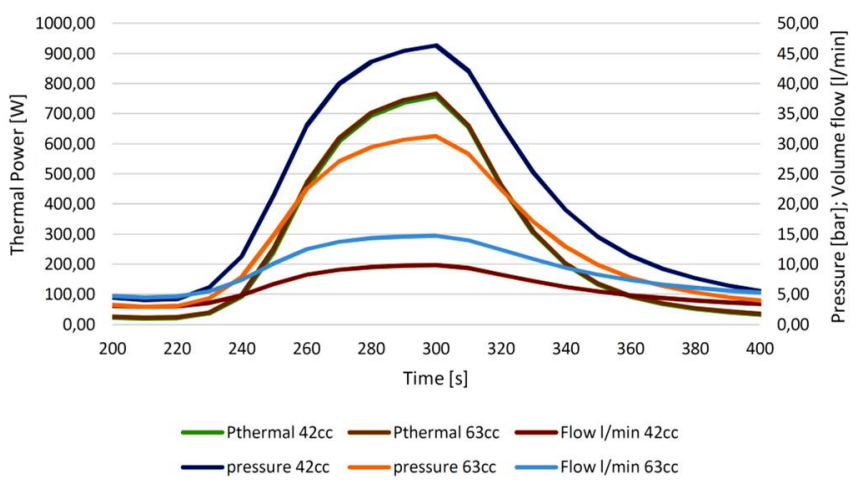

Fig. 11: Effect of pump size change to thermal power, pressure and volume flow.
Thermal power curves follow the same path. Changing the pump size does affect to the thermal power output in total by $2,4 \%$. With a pump with larger displacement the produced pressure reduces and volume flow increases.

\section{Simulation of the pressure relief valve}

Pressure in the fluid power circuit rises in proportion to the wind speed. Only high winds cause such a high pressure that the valve need to be opened. In Fig. 12 the rise of pressure is presented as a proportion wind speed change.

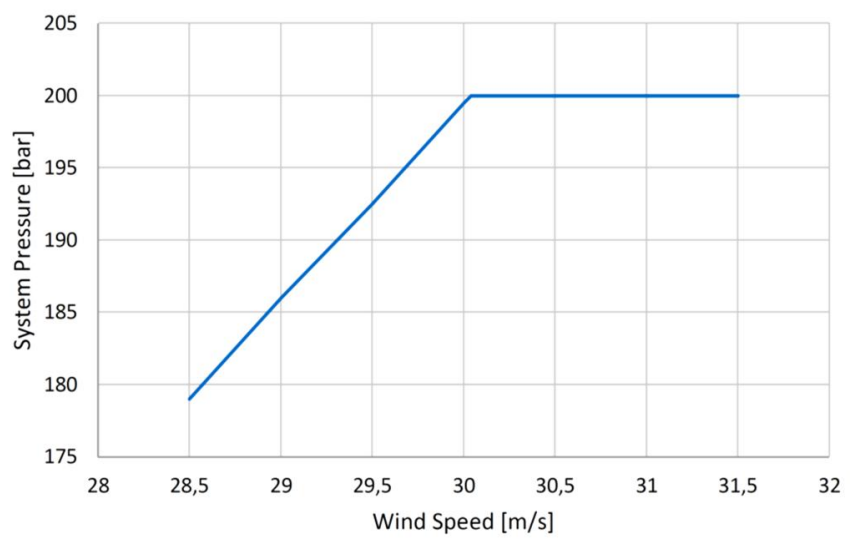

Fig. 12: Wind speed effect to system pressure.

Wind speed required to open the PRV with simulated rotor and pump is $30 \mathrm{~m} / \mathrm{s}$ for rotor $\left(C_{t}=0,25\right)$ when the pressure relief valve is set to 200 bars.

\section{Simulation of the throttle orifice}

Optimal orifice diameter for average wind speed is calculated for test rotor and pump. Optimal orifice diameter is needed to maximize the power output of the fluid power system. The changes in pump size, pump efficiency and torque coefficient $\left(C_{t}\right)$ changes the optimal orifice diameter. Rotor dimensions did not affect to optimal orifice size. Optimal orifice size for the simulated model is wind speed dependent as described in Fig. 14. Optimal throttle orifice diameter for rotor $\left(C_{t}=0,25\right)$ in wind speed of $v=10$ $\mathrm{m} / \mathrm{s}$ is presented in Fig. 13. Orifice diameter is interpolated from calculations and optimal diameter of $1,7 \mathrm{~mm}$ was found. Optimal orifice diameter for rotor $\left(C_{t}=0,35\right)$ in wind speed of $v=10 \mathrm{~m} / \mathrm{s}$ is $1,85 \mathrm{~mm}$. These orifice diameters related to $C_{t}$ values are used later in simulations.

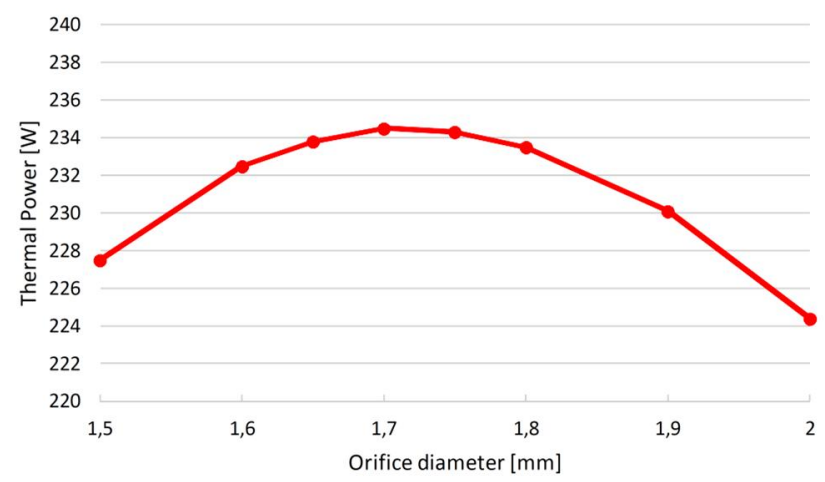

Fig. 13: Curve of optimal orifice diameter for test rotor $(\mathrm{Ct}=0,25)$ and pump. 
Wind speed affects to the optimal orifice size and this relation is presented in Fig. 14. Different constant wind speeds are used to assess the deviation between orifice diameter and tip speed ratio. Power locus curve presents the optimal wind speed ratio and orifice diameter for maximum thermal power for different wind speeds.

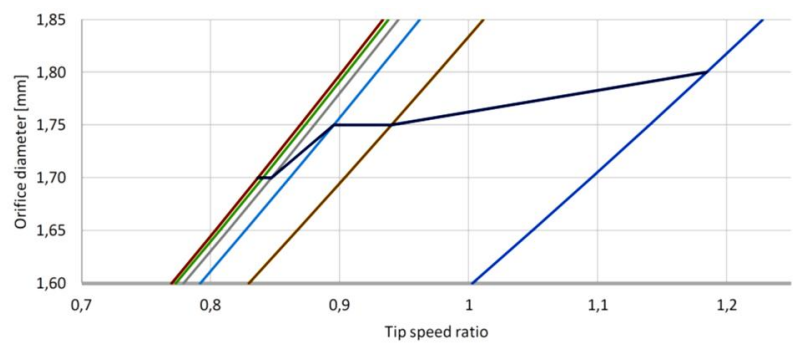

— $v=2 \mathrm{~m} / \mathrm{s}$ - $v=4 \mathrm{~m} / \mathrm{s}$ - $v=6 \mathrm{~m} / \mathrm{s}$ - $\mathrm{v}=8 \mathrm{~m} / \mathrm{s}$ - $\mathrm{v}=10 \mathrm{~m} / \mathrm{s}$ - $\mathrm{v}=12 \mathrm{~m} / \mathrm{s}$ —Power Locus

Fig. 14: Tip speed ratio change with different constant wind speeds.

Simulated changes in orifice size are causing maximum of $1,1 \%$ thermal power deviation in winds presented in Fig.14 and with calculated orifice sizes 1,6 to $1,85 \mathrm{~mm}$.

\section{E. Simulation of the oil tank}

Oil tank is a container with a breather and therefore there reigns atmospheric pressure in the tank. During every cycle the temperature in tank will increase due to returning fluid temperature. In this simulation tank volume is set to 10 liters. In Fig. 15 produced thermal power and temperature build up in tank is presented. Wind speed is set to constant $10 \mathrm{~m} / \mathrm{s}$. Radiator is excluded from the simulation to show the temperature rise in the hydraulic fluid and tank.

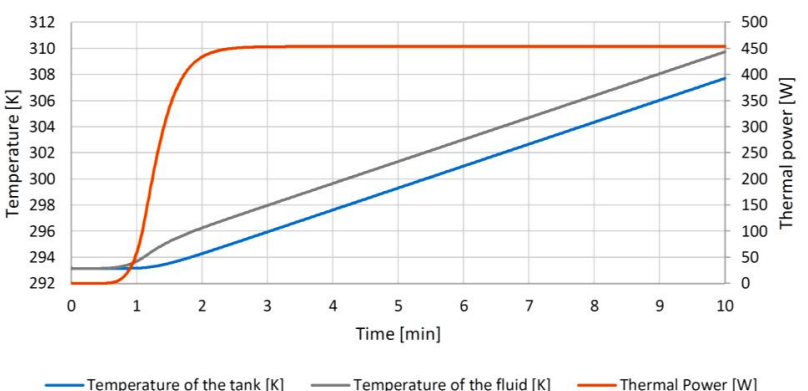

Fig. 15: Temperature build up in tank and thermal power.

\section{F. Temperature control in the system}

In this simulation the ambient temperature is $20^{\circ} \mathrm{C}$, also used set point temperature is $20^{\circ} \mathrm{C}$. When the set point temperature is reached the thermostat will open the flow path to the radiator. Pressure drop over the radiator is considered as inessential. Hysteresis of the thermostat is not simulated. The heated space and power requirement for the volume are not defined in this paper. In Fig. 16 and 17, produced thermal power and temperature build up in tank is presented. In Fig. 16 wind speed is set to constant $10 \mathrm{~m} / \mathrm{s}$. In Fig. 17 wind speed is following wind speed data from Fig. 4. Constants for radiator (Horizontal cylinder in air) $h_{r}=6,5$ $\mathrm{W} / \mathrm{m}^{2} \mathrm{~K}$ and $A=3 \mathrm{~m}^{2}$ are used. [23]

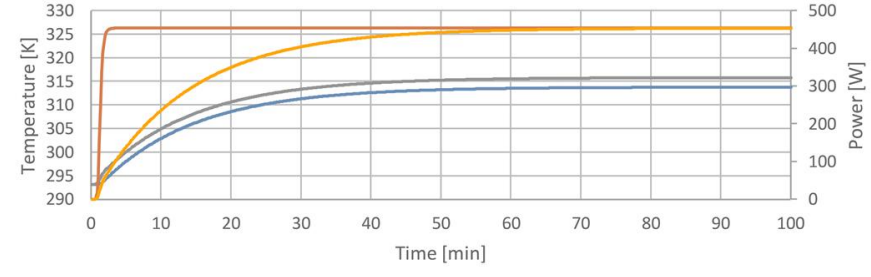

$$
\text { - Temperature of the tank }[\mathrm{K}] \longrightarrow \text { Temperature of the fluid }[\mathrm{K}]
$$

Fig. 16: Temperature build up for the tank and radiative power of the radiator.

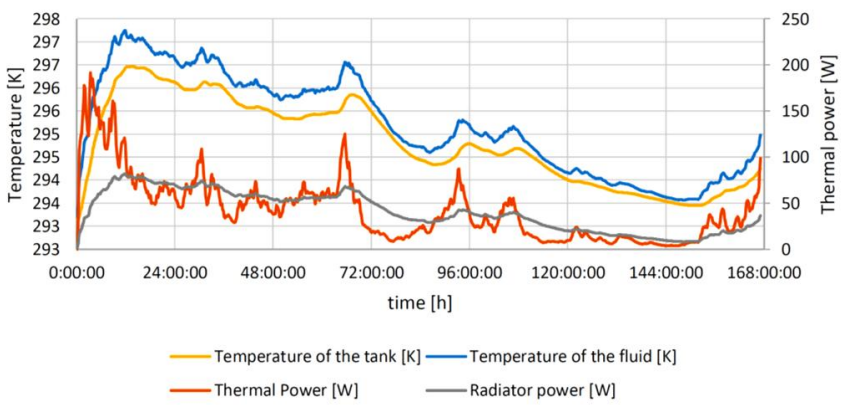

Fig. 17: Temperature build up for the tank and radiative power of the radiator in varied wind conditions.

\section{G. Effect of pipe volume to the system parameters}

Effect of the pipe volume to pressure and volume flow parameters was simulated. Simulation results are presented in Fig. 18. Volume of the pipe was modified. Used volumes are 0,7 liters, 7 liters and 35 liters. Wind speed pulse of 12 $\mathrm{m} / \mathrm{s}$ is used for input.

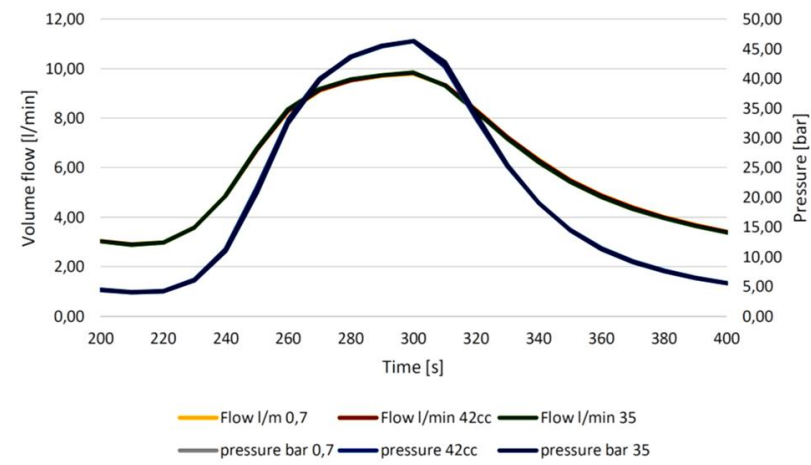

Fig. 18: Effect of pipe volume change to pressure and volume flow.

Results from this simulation are aligned with each other. Volume change in pipe between pump and orifice does not have an effect to results.

\section{H. Test bench configuration}

Test bench is assembled around integrated electrohydraulic energy converter (IEHEC) unit. [28] This simulation was implemented to estimate the test bench values and to control the frequency converter of IEHEC. Turbine simulation determines the power for the pump motor. Pump installed to IEHEC unit determines pump displacement for the simulator. Fixed displacement of the axial piston pump is $63 \mathrm{~cm}^{3} / \mathrm{rev}$. Optimal tip speed ratio is required for the rotor to transform maximum amount of wind energy to mechanical energy. Optimal tip speed ratio 
for system with an axial piston pump is achieved by adjusting the throttle orifice. Constant wind speed of 10 $\mathrm{m} / \mathrm{s}$ were used to calculate optimal orifice size and tip speed ratio. Different torque coefficient $C_{t}$ were used to study parameter effect for generated power and optimal tip speed ratio $\lambda$. These effects are presented in Fig. 19

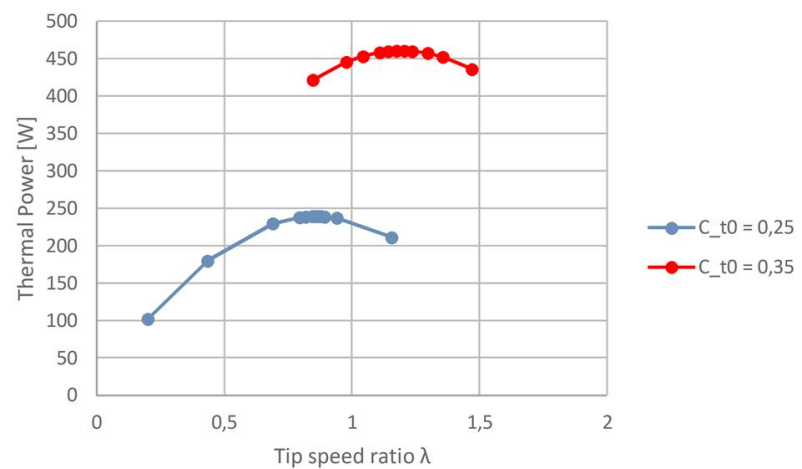

Fig. 19: Optimal tip speed ratio for different torque coefficient curves for IEHEC unit.

Optimal throttle orifice for rotor $T_{c}=0,25$ in wind speed of $v=10 \mathrm{~m} / \mathrm{s}$ is presented in Fig. 20. Orifice size is interpolated from calculations and optimal diameter of 2,35 $\mathrm{mm}$ was found. Optimal orifice diameter for rotor $T_{c}=0,35$ in wind speed of $v=10 \mathrm{~m} / \mathrm{s}$ is $2,5 \mathrm{~mm}$.

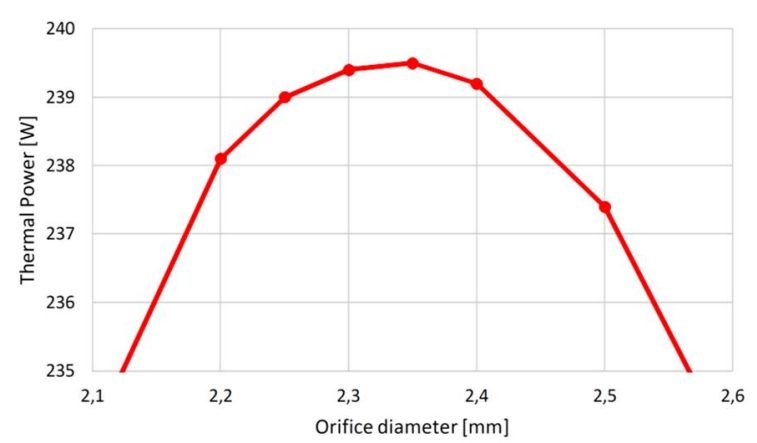

Fig. 20: optimal orifice diameter for test rotor and axial piston pump.

\section{Estimation of annual energy capture}

Wind speed varies dependent on day, month and a season of the year. Typically, in Finland the wind speeds are higher during the winter months. Changes in air pressure affect to wind speed variations and to wind gusts. Coasts are windy areas since there is temperature gradient and the warmer air is rising and this causes pressure differences. Over all local annual average wind speeds and wind power content can be calculated and used to estimate the production of a wind turbine in that area. Wind power content $P_{\text {uind }}[\mathrm{W}]$ is calculated usingEq. (21).

$P_{\text {wind }}=\frac{P_{t}}{\frac{1}{2} \rho A v^{3}}$

where is density of the air $\left[\mathrm{kg} / \mathrm{m}^{3}\right], A$ is area affected by the wind and $v$ is wind speed $[\mathrm{m} / \mathrm{s}]$. The power coefficient $C_{p}$ of the simulated system is calculated with equation (22) and the results for simulation are presented in Fig 21. Power coefficient for is presented for two torque coefficient, $C_{t}=$ 0,25 and $C_{t}=0,35$.
$C_{p}=\frac{1}{2} \rho A v^{3}$

where $P_{t}$ is thermal power [W].

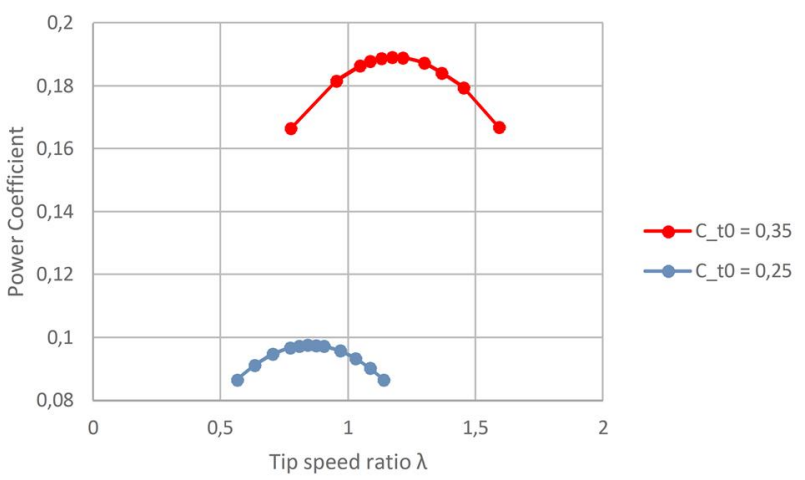

Fig. 21: Hydraulic power coefficient curves for Savonius rotor.

Power from average and RMS wind speed are presented with equivalent Simulink model results. With wind speed profile described in Fig. 8, produced thermal power is calculated for time period. Same period is simulated using Simulink. Also the annual power production with RMS wind speed and Simulink is compared. This annual power was calculated multiplying power average with hours per annum. The differences between calculated RMS and simulation results are $1 \%$. These results are presented to the table 1 .

TABLE 1: CALCULATED POWER VALUES FROM THE WIND DATA.

\begin{tabular}{|l|c|c|}
\hline Torque coefficient $(C t O)$ & 0,25 & 0,35 \\
\hline average wind speed [m/s] & \multicolumn{2}{|c|}{3,95} \\
\hline RMS of wind speed [m/s] & \multicolumn{2}{|c|}{4,44} \\
\hline Power of average wind speed [W] & 14,7 & 28,3 \\
\hline Power of RMS of wind speed [W] & 21,0 & 40,5 \\
\hline Simulated power of rotor [W] & 22,8 & 41,6 \\
\hline Total power produced by average wind speed [W] & 2453,3 & 4731,4 \\
\hline Total power produced by RMS of wind speed [W] & 3505,8 & 6761,3 \\
\hline Total simulated power [W] & 3803,8 & 6946,7 \\
\hline Total power production per annum (RMS) [kW/a] & 183,9 & 354,7 \\
\hline Total simulated power production per annum [kW/a] & 199,5 & 364,4 \\
\hline
\end{tabular}

Wind speed data in Fig. 8 is used to simulate the thermal power output of the system. In Fig. 22 two different power curves from wind data with torque coefficient of $C_{t}=$ 0,25 are presented. Power from the wind curve is calculated from wind data using Eq. 22 with optimal power coefficient of $C_{p}=0,098$. Simulink curve is from simulated wind data.

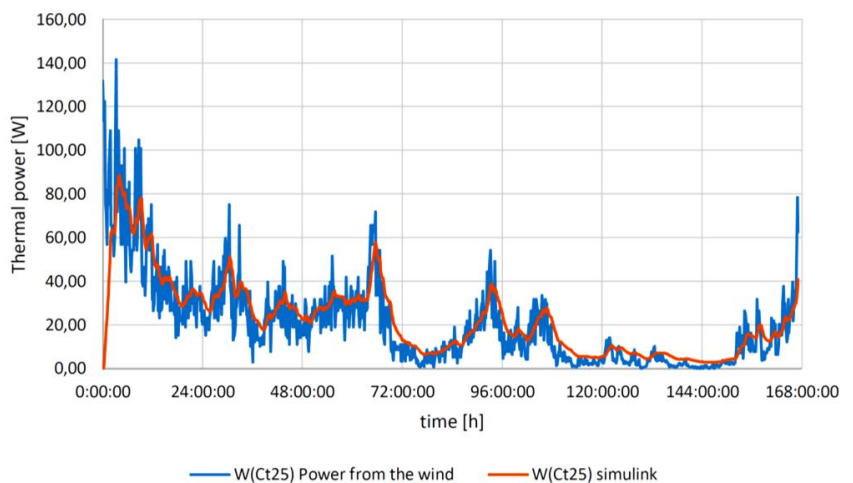

Fig. 22: Power curves from wind data with torque coefficient of $\mathrm{Ct}=0,25$. 
Wind speed data in Fig. 8 is used to simulate the thermal power output of the system. In Fig. 23 three different power curves from wind data with torque coefficient of $C_{t}=0,35$ are presented. Power from the wind curve is calculated from wind data using Eq. 22 with optimal power coefficient of $C_{p}=0,189$. Simulink curve is from simulated wind data. The effect of low inertia rotor was investigated in low inertia power curve.

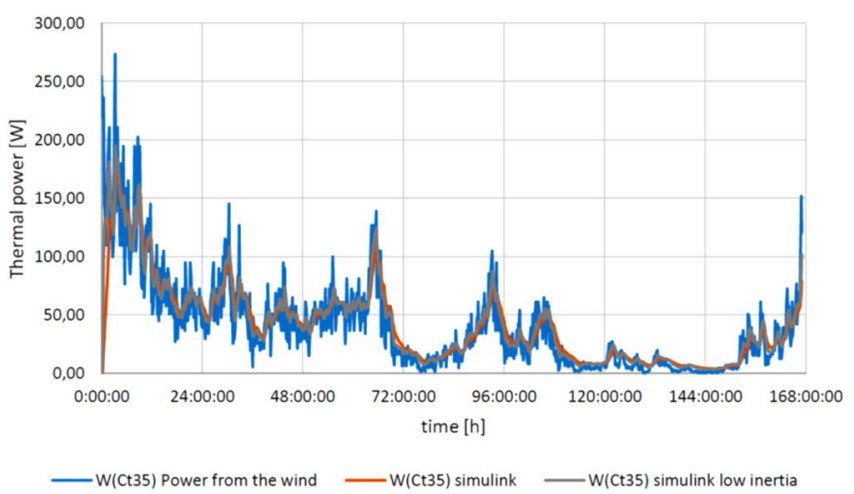

Fig. 23: Power curves from wind data with torque coefficient of $\mathrm{Ct}=0,35$.

Low inertia effect to the thermal energy output was investigated with $50 \%$ lighter rotor. This low inertia rotor gave efficiency difference between the rotors $1 \%$, while low inertia rotor created more total power.

\section{J. Key indicators of the investment}

After selecting the realistic assumptions for investment calculations the key indicators can be calculated.

TABLE 2: KEY INDICATORS FOR THE INVESTMENT. ENERGY PRICE WILL DEFINE THE ANNUAL INCOME HERE DESCRIBED AS ANNUAL SAVINGS.

\begin{tabular}{|l|c|c|}
\hline Capital cost & 8600 & $€$ \\
\hline Duration & 20 & years \\
\hline Energy price & 80 & $€ / \mathrm{MWh}$ \\
\hline Interest & 6 & $\%$ \\
\hline$C_{p}$ & 0,189 & \\
\hline Wind speed & 4,44 & $\mathrm{~m} / \mathrm{s}$ \\
\hline Total power annum & 355 & $\mathrm{kWh}$ \\
\hline Annual savings & 28 & $€$ \\
\hline Payback period & 303 & years \\
\hline Net present value & -8274 & $€$ \\
\hline Internal rate of return & $-18,2$ & $\%$ \\
\hline
\end{tabular}

Payback period is can be considered as ineligible since the estimation for unit use in operation is twenty years. Net present value, NPV is negative and does not support the assumption of profitable investment. Internal rate of return, IRR is negative due to relatively low annual savings.

\section{K. Sensitivity analyses}

In Fig. 24 average wind speed is manipulated in 20 years' period to reveal the required average wind speed for the simulated system. Net present value and internal rate of return curves presents the development of profitability in proportion to average wind speed.

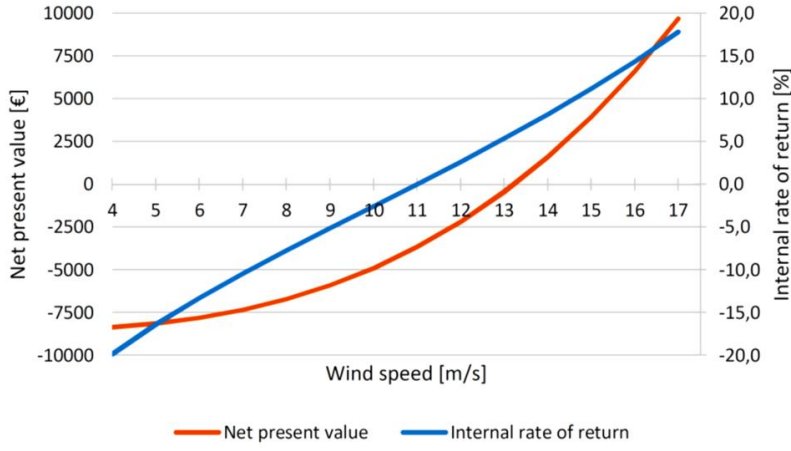

Fig. 24: Effect of average wind speed change to NPV and IRR for 20 years' period.

According net present value the investment of current configuration is profitable when the wind speed average is greater than $13,2 \mathrm{~m} / \mathrm{s}$. Internal rate of return becomes zero when the wind speed is greater than $11 \mathrm{~m} / \mathrm{s}$. A threshold wind speed for 20 years' payback period is also $11 \mathrm{~m} / \mathrm{s}$. Wind speed is the key factor for the investments profitability since it is proportional to the cube in the Eq. 22. All other parameters affecting the power output and profitability are progressing linearly. Economies of scale can be predicted for correlation between capital costs, rotor area and maximum output power.

Efficiency of the rotor, capital costs, interest rate and energy costs are insignificant when estimating the profitability of the investment with assumed wind speed $v=$ $4,4 \mathrm{~m} / \mathrm{s}$. In Fig. 25 average energy price is manipulated in 20 years' period to reveal the required average energy price for the simulated system. Net present value and internal rate of return curves presents the development of profitability in proportion to average energy price. The average wind speed is set for this estimation to $v=7 \mathrm{~m} / \mathrm{s}$. This is average wind speed in Finnish coastal areas.

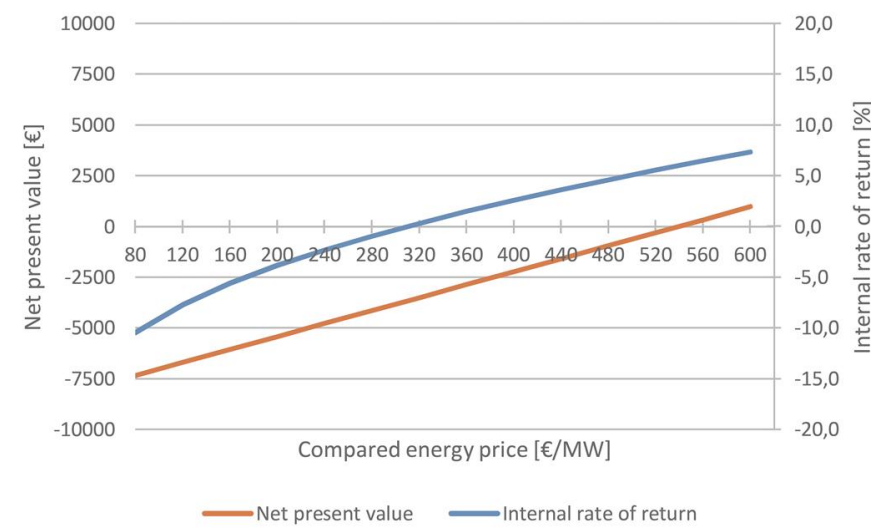

Fig. 25: Effect of compared energy price to NPV and IRR for 20-year period.

For net present value to be positive during 20 years hold time the compared energy price has to greater than 539 $€ / \mathrm{MW}$. Internal rate of return becomes zero when the energy price is greater than $309 € / \mathrm{MW}$. NPV is reached with wind speed of $v=4,4 \mathrm{~m} / \mathrm{s}$ when the energy price is $2170 € / \mathrm{MW}$. 


\section{V.CONCLUSIONS}

When the wind speed changes the optimal tip speed ratio also changes. This is caused by the changing resisting force in the fluid power circuit. Optimal orifice size and it's relation to the total thermal output was studied to solve the most effective value for orifice diameter. Since the thermal power deviation regarding tip speed ratio is considered to be small, needle valve is sufficient throttling device for simulated wind powered hydraulic heating circuit. Total efficiency of the wind powered heating system can be increased to some extent by electrically actuated valve that maintains the optimal tip-speed ratio by regulating pressure.

Changes in time step ( $T=5 \mathrm{~ms}$ to $1 \mathrm{~ms}$ ) length did not affect to the reliability and stability of the simulation significantly. Small values in pressure pipe volume between pump and throttle orifice caused the system to become stiff which influenced the numerical integrator stability. Investment for using the investigated wind rotor is not profitable under typical wind conditions. Parameters for the estimation were altered to solve the threshold of profitability. Under these estimations there is no reason to assume that the wind powered heating system as commercially profitable. Wind speed is the dominant parameter in the investment estimation.

Typical wind speeds in ground level reach very rarely to speeds that create needed heating power. Profitability of the wind powered heating source can be enhanced by increasing the installation height of the rotor, since higher wind speeds are present. During winter months in Finnish archipelago the wind speed reaches levels where unit reaches desired heat production. Different special circumstances where combustion or electricity is not possible or forbidden to use as energy wind powered heating unit can be used. Combined DarreiusSavonius-rotor increases the power coefficient of the wind rotor hence increasing the heating power output. Wind speed is the main factor that effects the profitability and this leads to conclusion that the profitability is a wind region dependent. Several patents closely concerning this unit are valid and might jeopardize the commercialization of this unit.

\section{REFERENCES}

[1] Ragheb, M. et al., Wind Turbines Theory - The Betz Equation and Optimal Rotor Tip Speed Ratio, [e-document] 2011, [referred 30.9.2014] Available: http://www.intechopen.com

[2] Freris, L., Infield, D., Renewable energy in power systems, John Wiley \& Sons, Ltd, 2009.

[3] Walker, J. F. et al., Wind Energy Technology, John Wiley \& Sons, 1997.

[4] Mitsubishi - Sea Angel 7MW [referred: 16.10.2014] Available http://www.4coffshore.com/windfarms/turbine-mitsubishi-powersystems-europe- seaangel-7-mw-tid83.html

[5] Savonius, S. J., The Wing Rotor in Theory and Practice, Savonius \& Co, Helsinki, 1926.

[6] Dabiri, J. O., Potential order-of-magnitude enhancement of wind farm power density via counter rotating vertical-axis wind turbine arrays, Journal of Renewable Sustainable Energy vol. 3, 2011.[referred 20.10.2014] http://dabiri.caltech.edu/publications/Da_JRSE11.pdf

[7] Jaohindy, P., An analysis of the transient forces acting on Savonius rotors with different aspect ratios, Renewable Energy vol. 55, 2013, p. 286-295.

[8] Fujisawa, N., On the torque mechanism of Savonius rotors, Journal of Wind Engineering and Industrial Aerodynamics vol. 40, Elsevier, 1992, p. 277-292.

[9] M.A. Kamoji, S.B.Kedare and S.V. Prabhu, "Performance tests on helical Savonius rotors," Renewable Energy vol. 34, 2009, p. 521529 .

[10] Nahar, S., Islam, Q., Ali, M., Torque and Drag Characteristics of a Six bladed Savonius Rotor, Mech. Eng. Dept., Bangladesh Univ. of Eng. \& Technol. (BUET), Dhaka, Bangladesh

[11] Zingman, A., Optimization of a Savonius Rotor Vertical-Axis Wind Turbine for Use in Water Pumping Systems in Rural Honduras, Massachesetts Institute of Technology, 2007.

[12] Wortman, A.J., Introduction to Wind Turbine Engineering, Boston, Butterworth Publishers, 1983.

[13] Sharma, K.K., Biswas, A., Gupta, R., Performance Measurement of a Three-Bladed Combined Darrieus-Savonius Rotor, International Journal of Renewable Energy Research, Vol. 3, No. 4, 2013.

[14] Handroos, H. Methods for Combining a Theoretical and Empirical Approach in Modelling Pressure and Flow Control Valves for CAE programs for Fluid Power Circuits. PhD thesis, Tampere University of Technology, 1991.

[15] Åman, R., Hydraulisen kuristinmallin ja liikejalustan ohjauksen kehittäminen reaaliaika simulointiin (in Finnish), M.Sc. thesis, Lappeenranta University of Technology, 2007.

[16] Kauranne, H. et al., Hydrauliikan perusteet(in Finnish), WSOY Porvoo, 1996.

[17] Munson, B. R. et al., Fundamentals of Fluid Mechanics, $4^{\mathrm{Th}}$ edition, John Wiley \& Sons, Inc., 2002.

[18] Airila, M. et al., Koneenosien suunnittelu(in Finnish), WSOY, 1995.

[19] Sathyajith M., Wind Energy Fundamentals, Resource Analysis and Economics, Springer, 2006.

[20] Manring, N. D., Hydraulic Control Systems, John Wiley \& Sons, Inc. 2005.

[21] Merrit, H. E., Hydraulic Control Systems, John Wiley \& Sons, Inc., 1967.

[22] Handroos, H. M., Vilenius, M. J., The Utilization of Experimental Data in Modelling Hydraulic Single Stage Pressure Control Valves, Journal of Dynamic Systems, Measurement and Control Vol. 112, September 1990, p. 482-488.

[23] Holman, J. P., Heat Transfer, McGraw-Hill Book Company, 1989.

[24] Finnish meteorological institute - Winds [referred 23.10.2014] Available: http://ilmatieteenlaitos.fi/tuulet (in Finnish).

[25] Wind data - database [referred 21.10.2014] Available: http://data.fmi.fi/fmiapikey/personalapikeyhere/wfs?request=GetFeature \&storedquery_id=fmi::observations::weather::timevaluepair\&place=ku mpula\&parameter $=$ windspeedms \&starttime $=2014-02$ 01T00:00:00Z\&endtime $=2014-02-07 \mathrm{~T} 23: 00: 00 Z \&$ timestep $=1$, Database requires personal api-key.

[26] District Heating prices in Finland, Kaukolämmön hinnat 1.7.2014 (xls) $\begin{array}{lll}\text { [referred 23.10.2014] Available: } & \end{array}$ http://energia.fi/tilastot/kaukolammon-hinnat- tyyppitaloissa-eripaikkakunnilla

[27] Electricity prices in Finland, Sähkön siirron verkonhaltijakohtaiset keskihinnat kuluvalta kuukaudelta (xls) [referred 23.10.2014] Available: http://www.energiavirasto.fi/sahkon-hintatilastot

[28] Ponomarev, P. et al. High Power Density Integrated ElectroHydraulic Energy Converter for Heavy Hybrid Off-Highway Working Vehicle, IET Electrical Systems in Transportation, 2014, p. $1-8$. 